\title{
Heritability of head size in the common gull Larus canus in relation to environmental conditions during offspring growth
}

\author{
KJELL LARSSON*†, KALEV RATTISTE† \& VILJU LILLELEHT \$ \\ $\uparrow$ Department of Zoology, Uppsala University, Villavägen 9, S-752 36 Uppsala, Sweden and †/nstitute of Zoology and \\ Botany, Riia 181, EE-2400 Tartu, Estonia
}

\begin{abstract}
We studied the heritability of head length in a common gull (Larus canus) population breeding in western Estonia. Heritability estimates obtained from offspring-parent regressions were moderate to high and significantly different from zero. Head size might hence respond evolutionarily to phenotypic selection. Offspring-mother and offspring-father regressions yielded similar heritability estimates. This indicated that size-related maternal or paternal effects were absent or weak. Heritability and additive genetic variance estimates obtained from offspringparent regressions and full-sib analyses were higher when offspring had grown up under good environmental conditions than under poor environmental conditions. Such a pattern has previously been found in some other studies of birds. This suggests that genotype-environment interactions might be frequent within the range of conditions experienced by natural bird populations.
\end{abstract}

Keywords: body size, common gull, genotype-environment interaction, heritability, Larus canus, maternal effects.

\section{Introduction}

The inheritance of ecologically important traits in natural populations has received increased interest in recent years. This is because knowledge about heritabilities and genetic correlations is necessary if one wants to make predictions about genetic responses to selection or reconstructions of evolutionary changes in the past (Lande, 1976, 1979; Lande \& Arnold, 1983; Falconer, 1989). One of the first attempts to measure heritabilities and genetic correlations in wild bird populations was made in the 1970s as part of a study of Darwin's finches (Boag \& Grant, 1978). Since then, numerous observational and cross-fostering studies of birds have provided evidence of morphological traits often being heritable and positively genetically correlated with each other (Grant, 1986; Boag \& van Noordwijk, 1987; Larsson \& Forslund, 1992; Merilä \& Gustafsson, 1993). It has also been found that physiological, behavioural and life history traits can be significantly heritable in natural bird populations (van Noordwijk et al., 1980, 1981; Mousseau \& Roff,

${ }^{*}$ Correspondence. E-mail: kjell.larsson@zoologi.uu.se*Correspondence: e-mail: Kjell.Larsson@zoologi.uu.se
1987; Berthold et al., 1992; Schluter \& Gustafsson, 1993; Larsson, 1996).

To be able to make accurate predictions about genetic responses to selection in heterogeneous natural environments, one needs to know not only the variability of selection pressures, but also whether heritability and genetic correlation estimates commonly vary over time and space (Arnold, 1981; Via \& Lande, 1985; Gebhardt-Henrich \& van Noordwijk, 1991; Larsson, 1993; Merilä, 1996). It is also necessary to identify the mechanisms that may cause variation in the estimates of genetic parameters. For example, the amount of additive genetic variance may vary because genes are expressed differently under different environmental conditions, i.e. there may be significant genotype-environment interactions (Falconer, 1989). However, in natural populations it is also possible that maternal and paternal effects, as well as other genetic and nongenetic mechanisms, might affect the estimates of genetic parameters differently under different conditions.

A very prominent difficulty in quantitative genetic studies of natural populations is to obtain large enough samples of related individuals to reduce standard errors of heritability estimates and genetic 
correlations to a level at which comparisons between different estimates become meaningful. Consequently, so far, only a few studies have been able to make specific analyses of the variability of genetic parameters under natural conditions.

The aim of this study was to examine the inheritance of head size in a natural population of the common gull (Larus canus). We used an unusually large data set of related individuals to analyse the variability of heritability estimates obtained under different environmental conditions. We also investigated whether the observed variability might be explained by the presence of maternal or paternal effects on offspring size.

\section{Methods}

Common gulls were studied between 1968 and 1983 and between 1986 and 1995 in the Matsalu Nature Reserve in western Estonia $\left(58^{\circ} 46^{\prime} \mathrm{N} ; 23^{\circ} 26^{\prime} \mathrm{E}\right)$. The study site consisted of three breeding colonies on three small islands situated about $1 \mathrm{~km}$ apart close to the coast. This site is one of the most favourable for breeding common gulls in western Estonia, and a long-term study of the breeding biology of the common gull has been in progress at this site since 1962 (Onno, 1965, 1967a,b, 1968; Rattiste, 1983; Rattiste \& Lilleleht, 1986, 1987, 1995). The total number of breeding pairs in the three colonies together varied between 212 and 380 pairs during the study period.

Unmarked breeding birds were captured with traps on nests in each year. Captured birds were ringed with aluminium rings and with coloured plastic leg rings which were identifiable at a distance. About 92 per cent of the nest owners in the colonies were identified in each year, either by catching or by resighting. Nestlings were ringed with aluminium rings when about one day old. About 95 per cent of all nestlings in the colonies were ringed in each year. Common gulls usually recruit to the breeding population when 2-5 years old (mean $=3.5$ years). The local recruitment rate, the recruitment rate to the study area of birds ringed as nestlings, differed between the sexes, with males showing a higher degree of natal fidelity (Rattiste \& Lilleleht, 1986). Thus, of 628 local recruits which were captured and measured about 81.5 per cent were males. The captured recruits were all marked with coloured rings.

Head length, the distance from the tip of the bill to the back of the head, of captured adults was measured with a calliper to the nearest $0.5 \mathrm{~mm}$. In some years the tarsus length, wing length and body weight were also measured. Measurements of these additional body size traits were moderately positively correlated with head length (Pearson correlation coefficients ranging between +0.16 and +0.42 ). Almost all of the birds have been measured by one of the authors (KR). The repeatability (Lessells \& Boag, 1987) of head length measurements of the same adult birds in different years was high (rep. $=0.96, n=516, F=53.54, P<0.001$ ). Head lengths of 25- to 27-days-old chicks were also measured between 1971 and 1981 by Aime Laidna as described above.

The sex of adult birds was determined from measurements of head length. Males are usually larger than females (mean $=94.00, \quad \mathrm{SD}=2.16$, $n=1805 ;$ mean $=87.12, \mathrm{SD}=2.07, n=1820$, for males and females, respectively), and results from an earlier study have shown that measurements of head length can be used to sex adult common gulls reliably (Onno, 1967a). In addition, the sex of marked adults was also controlled by observing their copulating behaviour and/or confirmed by the body size and behaviour of previous partners.

We classified growth conditions for 23 different cohorts of gulls (the 23 year-classes of gulls born between 1968 and 1983 and between 1986 and 1992) by using the mean head length of recruits as the classification criterion. The underlying assumption for this classification was that the mean head length values of recruits from different cohorts would, to some extent, reflect the environmental conditions to which these cohorts were exposed during growth. This assumption was corroborated by our finding that yearly mean values of head length of 25 - to 27-days-old chicks correlated positively with mean head length of recruits from the corresponding cohorts $(r=0.68, n=11$ years, $P=0.02)$. It has also been shown in studies of many other bird species that environmental conditions during growth affect final adult structural body size (Boag, 1987; Smith et al., 1989; Larsson \& Forslund, 1991; Cooke et al., 1995). Thus, to classify growth conditions for the 23 different cohorts, we ranked the mean head length values of recruits. The recruits belonging to the eight cohorts with the lowest ranks, the seven cohorts with intermediate ranks, and the eight cohorts with the highest ranks were classified as having been exposed to poor, normal and good growth conditions, respectively.

Heritability estimates $\left(h^{2}\right)$ for head length were obtained by offspring-parent regression and by fullsib analyses (Falconer, 1989; Becker, 1984). It was not possible to calculate heritabilities for other morphological traits because data were too few. 
Males have occasionally been observed to try to copulate with females other than their partners. At present we have no data on the success of such extra-pair copulations. Therefore, in this paper we assume that all recruits originating from the same nests were full-sibs and the true offspring of both nest owners. Recruits raised by the same parents in different years were also assumed to be full-sibs. Before heritability of head length was estimated, female measurements were standardized to male equivalents by multiplying the female head length measurements with 1.0790 (a constant reflecting the ratio of mean male/female head length observed in a larger sample, $n=3625$ ). After this standardization no differences in means or variances between the sexes were found. The heritability estimates from the offspring-parent regressions are not corrected for the slight variation in offspring number per family because the inclusion of possible alternative weighing procedures (Falconer, 1989; Cooke et al., 1995 ) had only minimal effects. Differences between heritability estimates obtained by offspring-parent regressions were tested with a heterogeneity of slopes model (SAS Institute Inc., 1987). Additive genetic variances $\left(V_{\mathrm{A}}\right)$ were estimated as twice the covariance between offspring and parents, and in the full-sib analyses as twice the between-family variance component. The $V_{\mathrm{A}}$ estimates from analyses of fullsibs will be inflated if there are effects of dominance variance or common environment effects (Falconer, 1989). The presented variance components were estimated using the procedure VARCOMP, method = type 1 (SAS Institute Inc., 1987). An alternative method to estimate the variance components, the restricted maximum likelihood method (procedure VARCOMP, method = REML (SAS Institute Inc., 1987), produced very similar estimates. It should be noted that all offspring were measured when recruiting to the breeding population. Hence, only measurements of offspring which had survived at least two winters were included in the heritability analyses.

\section{Results \\ Head length of birds included in heritability analyses}

The mean head lengths of birds included in the heritability analyses are shown in Table 1 . There were highly significant differences between mean head length of offspring that were classified as having been exposed to poor, normal and good growth conditions, respectively. The mean head lengths of offspring exposed to poor growth conditions were, on average, about 0.5 standard deviations shorter than the mean head lengths of offspring exposed to good growth conditions. These differences are expected because we used the mean head length of offspring cohorts as the classification criterion. However, there were no significant differences in mean head length between the parents in the corresponding groups (Table 1). The mean head lengths of offspring exposed to poor and normal growth conditions were significantly shorter than the mean head lengths of their parents $(t=-4.39$, $P<0.001 ; t=-3.27, P<0.01, t$-tests, respectively), whereas no significant difference was observed between the mean head length of offspring exposed to good growth conditions and the mean head length of their parents $(t=0.59, P>0.50, t$-test $)$. The phenotypic variance in head length did not differ significantly among offspring or parents in the three groups (all $P>0.10$, Bartlett's test for homogeneity of variances).

\section{Heritability estimates}

Heritability estimates and estimates of additive genetic variances obtained from offspring-midparent and

Table 1 Mean head length (mm) of offspring and parent common gulls included in offspring-parent regressions. Poor, normal and good refer to environmental conditions during offspring growth (see Methods). Female measurements were adjusted to male equivalents. Differences between mean values were tested with ANOVA

\begin{tabular}{|c|c|c|c|c|c|c|c|c|c|c|c|}
\hline & \multicolumn{3}{|c|}{ Poor } & \multicolumn{3}{|c|}{ Normal } & \multicolumn{3}{|c|}{ Good } & \multicolumn{2}{|c|}{ ANOVA } \\
\hline & $n$ & Mean & $\mathrm{SD}$ & $n$ & Mean & $\mathrm{SD}$ & $n$ & Mean & $\mathrm{SD}$ & $F$ & $P$ \\
\hline Offspring* & 111 & 93.32 & 1.86 & 137 & 93.84 & 1.69 & 175 & 94.27 & 1.87 & 9.37 & $<0.0001$ \\
\hline Midparents & 111 & 94.35 & 1.63 & 137 & 94.46 & 1.42 & 175 & 94.16 & 1.62 & 1.48 & 0.23 \\
\hline Mothers & 141 & 94.28 & 1.98 & 162 & 94.45 & 1.96 & 192 & 94.21 & 2.12 & 0.65 & 0.52 \\
\hline Fathers & 136 & 94.44 & 2.26 & 159 & 94.32 & 1.95 & 189 & 94.15 & 2.20 & 0.75 & 0.47 \\
\hline
\end{tabular}

*Sample of offspring used in offspring-midparent regressions. 
offspring-single parent regressions are shown in Table 2. All the offspring-parent regressions were significantly positive. The heritability estimates obtained from offspring-midparent regressions when offspring had been exposed to poor, normal and good growth conditions, respectively, were significantly different $\left(F_{2,417}=4.01, P<0.05\right.$, homogeneity of slopes test) (Table 2). The heritability estimates obtained under poor conditions were lowest and those obtained under good conditions were highest. A similar pattern was observed for heritability estimates obtained from single-parent regressions, although the differences were not statistically significant $\left(F_{2,489}=1.89, P=0.15 ; F_{2,478}=1.80, P=0.17\right.$, for offspring-mother and offspring-father regressions, respectively).

The heritability estimates obtained from the offspring-mother and offspring-father regressions were not significantly different from each other in any of the three groups $\left(F_{1,273}=0.41, P=0.52\right.$; $F_{1,317}=0.00, P=0.99$; and $F_{1,377}=1.09, P=0.30$; for poor, normal and good offspring growth conditions, respectively, homogeneity of slopes tests).

The heritability estimates obtained from the fullsib analyses were similar to or higher than the corresponding estimates from offspring-parent regressions (Table 2). The heritability and the additive genetic variance estimate from the analysis of fullsibs exposed to poor environmental conditions was lower than estimates obtained from analyses of fullsibs exposed to normal or good conditions (Table 2).

\section{Discussion}

By analysing a large data set of related common gulls we found that head length was significantly heritable. Thus, head length can be expected to respond evolutionarily to phenotypic selection. Our finding is in accordance with several previous studies which have found that morphological traits of various organisms usually are moderately or highly heritable in nature (Boag \& van Noordwijk, 1987; Mousseau \& Roff, 1987; Larsson \& Forslund, 1992; Merilä \& Gustafsson, 1993).

We also found that heritability and additive genetic variance estimates obtained from offspringparent regressions and full-sib analyses differed across environments, such that estimates were higher when offspring had grown up under good environmental conditions than under poor environmental conditions. Experiments performed under controlled laboratory or greenhouse conditions have shown that heritability and genetic correlation estimates can differ considerably between different plant and animal populations because of genotype-environment interactions (Mitchell-Olds \& Rutledge, 1986; Hoffmann \& Parsons, 1993). However, the results so far obtained from such experiments are equivocal in respect to whether heritabilities usually increase or decrease under stressful conditions (Hoffmann \& Parsons, 1993). Although data from natural populations are scarce, the results from this and some other recent studies of birds suggest that heritability estimates usually decrease under poor growth conditions (Price, 1985; van Noordwijk et al., 1988; Wiggins, 1989; GebhardtHenrich \& van Noordwijk, 1991; Larsson, 1993; Smith, 1994; Merilä, 1996; but see Boag, 1983). In some studies, the lower heritability estimates obtained under poor conditions might have resulted from an increased environmental variance (van Noordwijk et al., 1988; Simons \& Roff, 1994; Smith, 1994). However, in this study we found no significant differences in the phenotypic variance among offspring or parents in the three analysed groups. The lower heritability estimates obtained under poor offspring growth conditions therefore cannot be ascribed solely to an increased environmental vari-

Table 2 Heritability $\left(h^{2}\right)$ and additive genetic variance $\left(V_{\mathrm{A}}\right)$ estimates for head length in a common gull population in relation to environmental conditions during offspring growth. $n=$ number of families. The mean number of offspring per family are given in brackets. SE $=$ standard error of $h^{2}$ estimates. Asterisks indicate that heritability estimates are significantly different from zero

\begin{tabular}{|c|c|c|c|c|c|c|c|c|c|c|c|c|}
\hline & \multicolumn{4}{|c|}{ Poor } & \multicolumn{4}{|c|}{ Normal } & \multicolumn{4}{|c|}{ Good } \\
\hline & $n$ & $V_{\mathrm{A}}$ & $h^{2}$ & $\mathrm{SE}$ & $n$ & $V_{\mathrm{A}}$ & $h^{2}$ & $\mathrm{SE}$ & $n$ & $V_{\mathrm{A}}$ & $h^{2}$ & SE \\
\hline Offspring-midparent & $111(1.1)$ & 2.04 & 0.38 & $0.10^{* * *}$ & $137(1.2)$ & 1.87 & 0.46 & $0.09^{* * *}$ & $175(1.2)$ & 3.68 & 0.70 & $0.07^{* * *}$ \\
\hline Offspring-mother & $141(1.2)$ & 2.06 & 0.53 & $0.16^{* * *}$ & $162(1.3)$ & 2.58 & 0.67 & $0.13^{* * *}$ & $192(1.3)$ & 3.95 & 0.88 & $0.11^{* * *}$ \\
\hline Offspring-father & $136(1.2)$ & 2.00 & 0.39 & $0.15^{* *}$ & $159(1.3)$ & 2.58 & 0.67 & $0.14^{* * *}$ & $189(1.3)$ & 3.46 & 0.71 & $0.12^{* * * *}$ \\
\hline Full-sibs & $19(2.2)$ & 0.64 & 0.27 & 0.43 & $29(2.3)$ & 3.01 & 0.79 & $0.29^{* *}$ & $37(2.2)$ & 4.91 & 1.22 & $0.19 * * *$ \\
\hline
\end{tabular}

${ }^{* *} P<0.01, * * * P<0.001$. 
ance. It might also be argued that phenotypic selection on head size up to the time of recruitment might vary in strength and that strong truncation selection in certain years or environments can affect the amount of phenotypic and additive genetic variation and hence the observable heritabilities. Again, the absence of significant differences in phenotypic variance among recruiting offspring suggests that possible truncation selection on head size up to the time of recruitment was not considerably different in the three analysed groups of offspring.

Extra-pair fertilizations, as well as maternal or paternal effects, have, in other studies, been found to cause differences between slopes of offspringmother and offspring-father regressions (Larsson \& Forslund, 1992; Møller \& Birkhead, 1992; Potti \& Merino, 1994). However, we found no significant differences between slopes of offspring-mother and offspring-father regressions in any of the three environments. This indicates that size-related maternal or paternal effects, or effects of extra-pair fertilizations, were absent or weak. Hence, the observed differences between heritability estimates under different environmental conditions most probably were not caused by unequal rates of extra-pair fertilizations, or by unequal strengths of maternal or paternal effects in the different environments. We therefore suggest that the different heritability and additive genetic estimates obtained in this study were a consequence of genotype-environment interactions, and that different genotypes were expressed differently in different environments (had non-parallel reaction norms) (Stearns, 1992). Offspring classified as having grown up under poor and normal conditions were, on average, significantly smaller than their parents, whereas the mean body size of offspring classified as having grown up under good conditions was similar to the mean body size of their parents. We find it likely that the environmental conditions during growth can affect a bird's chance to produce recruits, and hence, that parents that were able to produce recruiting offspring in general had experienced better growth conditions than those that did not produce any recruits. The presented heritability estimates obtained when offspring had grown up under poor conditions, therefore, should not necessarily be expected to be equal to the heritability estimates obtained when both offspring and parents had experienced poor growth conditions (Coyne \& Beecham, 1987; Riska et al., 1989). Unfortunately, we could not reliably test whether the slope of the assumed cross-environmental offspring-parent regression was different from an offspring-parent regression when both generations had experienced poor growth conditions. The sample of parents of known year of birth was too small for such an analysis.

In conclusion, the results of this and other studies suggest that estimates of genetic parameters such as heritabilities and genetic correlations may vary even within relatively short time periods in natural populations because of the presence of genotypeenvironment interactions. If the influences of genotype-environment interactions on the phenotypic variation are usually large, then it follows that predictions or reconstructions of genetic responses to selection over longer time periods in spatially or temporarily heterogeneous environments might be unreliable (Mitchell-Olds \& Rutledge, 1986; Turelli, 1988; Stearns, 1992). More empirical studies are therefore needed to evaluate the limits within which the important quantitative genetic parameters usually vary in natural populations.

\section{Acknowledgements}

Sven Onno started a long-term study in 1962 of the breeding biology of the common gull in Estonia. Without his pioneering work this study would not have been possible. We thank all the voluntary field assistants who have helped us to collect data during all the years. We especially thank Aime Laidna and Eve Mägi for their huge contribution in data gathering. Kjeld Pedersen, Johnny Pedersen and Eddie Fritze kindly provided us with colour rings. We also thank James Fry, Juha Merilä and Staffan Ulfstrand for discussions and comments on the manuscript. Financial support was provided by the Estonian Science Foundation, the Swedish Institute (grant to K.R.) and the Swedish Natural Science Research Council (grant to K.L.).

\section{References}

ARNOLD, s. J. 1981. Behavioural variation in natural populations. I. Phenotypic, genetic and environmental correlations between chemoreceptive responses to prey in the Garter Snake, Thamnophis elegans. Evolution, 35, 489-509.

BECKer, w. A. 1984. Manual of Quantitative Genetics. Academic Enterprises, Pullman, WA.

BERTHOLD, P., HELBIG, A. J., MOHR, G. AND QUERNER, U. 1992. Rapid microevolution of migratory behaviour in a wild bird species. Nature, 360, 668-670.

BOAG, P. T. 1983. The heritability of external morphology in Darwin's ground finches (Geospiza) on Isla Daphne Major, Galapagos. Evolution, 37, 877-894. 
BOAG, P. T. 1987. Effects of nestling diet on growth and adult size of zebra finches (Poephila guttata). Auk, 104, 155-166.

BOAG, P. T. AND GRANT, P. R. 1978. Heritability of external morphology in Darwin's Finches. Nature, 274, 793-794.

BOAG, P. T. AND VAN NOORDWIJK, A. J. 1987. Quantitative genetics. In: Cooke, F. and Buckley, P. A. (eds) Avian Genetics, pp. 45-78. Academic Press, London.

COOKE, F., ROCKWELl, R. F. AND LANK, D. B. 1995. The Snow Geese of La Pérouse Bay. Oxford University Press, Oxford.

COYNE, J. A. AND BEECHAM, E. 1987. Heritability of two morphological characters within and among natural populations of Drosophila melanogaster. Genetics, 117, 727-737.

FALCONER, D. S. 1989. Introduction to Quantitative Genetics, 3rd edn. Longman Scientific and Technical, New York.

GEBHARDT-HENRICH, S. G. AND VAN NOORDW1JK, A. J. 1991. Nestling growth in the Great Tit. I. Heritability estimates under different environmental conditions. $J$. Evol. Biol., 3, 341-362.

GRANT, P. R. 1986. Ecology and Evolution of Darwin's Finches. Princeton University Press, Princeton, NJ.

HOFFMANN, A. A. AND PARSONS, P. A. 1993. Evolutionary Genetics and Environmental Stress. Oxford University Press, Oxford.

LANDE, R. 1976. Natural selection and random genetic drift in phenotypic evolution. Evolution, 30, 314-334.

LANDE, R. 1979. Quantitative genetic analyses of multivariate evolution, applied to brain:body size allometry. Evolution, 33, 402-416.

LANDE, R. AND ARNOLD, s. J. 1983. The measurement of selection on correlated characters. Evolution, 37, 1210-1226.

LARSSON, K. 1993. Inheritance of body size in the Barnacle Goose under different environmental conditions. $J$. Evol. Biol., 6, 195-208.

LARSSON, K. 1996. Genetic and environmental effects on the timing of wing moult in the barnacle goose. Heredity, 76, 100-107.

LARSSON, K. AND FORSLUND, P. 1991. Environmentally induced morphological variation in the Barnacle Goose, Branta leucopsis. J. Evol. Biol., 4, 619-636.

LARSSON, K. AND FORSLUND, P. 1992. Genetic and social inheritance of body size and egg size in the barnacle goose (Branta leucopsis). Evolution, 46, 235-244.

LESSELLS, C. M. AND BOAG, P. T. 1987. Unrepeatable repeatabilities: a common mistake. Auk, 104, 116-121.

MERILÄ, J. 1996. Genetic and Quantitative Trait Variation in Natural Bird Populations. Ph.D. Thesis, University of Uppsala.

MERILÄ, J. AND GUSTAFSSON, L. 1993. Inheritance of size and shape in a natural population of collared flycatchers, Ficedula albicollis. J. Evol. Biol., 6, 375-395.

MITCHELL-OLDS, T. AND RUTLEDGE, J. J. 1986. Quantitative genetics in natural plant populations: a review of the theory. Am. Nat., 127, 379-402.
MøLLER, A. P. AND BIRKHEAD, T. R. 1992. Validation of the heritability method to estimate extra-pair paternity in birds. Oikos, 64, 485-488.

MOUSSEAU, T. A. AND ROFF, D. A. 1987. Natural selection and the heritability of fitness components. Heredity, 59, 181-197.

ONNO, s. 1965. Attachment to the nest (Ortstreue) in the Common Gull, Common Tern and Arctic Tern. Communications of the Baltic Commission for the Study of Bird Migration, 3, 140-162.

ONNO, s. 1967a. Nesting ecology of the Common Gull. In: Kumari, E. (ed.) Lääne-Eesti meresaarte linnustik. Ornitoloogiline kogumik, vol. 4, pp. 114-148. Estonian Academy of Sciences, Tartu. (In Estonian with English summary.)

ONNO, s. $1967 \mathrm{~b}$. Mortality of the Common Gull in the light of ringing data. Communications of the Baltic Commission for the Study of Bird Migration, 4, 109-127. (In Russian with English summary.)

ONNO, s. 1968. The life span of the Common Gull and the age structure of its population in Estonia. Communications of the Baltic Commission for the Study of Bird Migration, 5, 81-109. (In Russian with English summary.)

POTT1, J. AND MERINO, s. 1994. Heritability estimates and maternal effects on tarsus length in pied flycatchers, Ficedula hypoleuca. Oecologia, 100, 331-338.

PRICE, T. D. 1985. Reproductive responses to varying food supply in a population of Darwin's finches: clutch size, growth rates and hatching synchrony. Oecologia, 66, 411-416.

RATTISTE, K. 1983. Distribution of the West-Estonian Common Gull Larus canus in the non-breeding period. Ornis Fennica, Suppl., 3, 61-62.

RATTISTE, K. AND LILlELEHT, v. 1986. Some aspects of the demography of the Common Gull Larus canus in Estonia. Vår Fågelvärld, Suppl., 11, 179-186.

RATtiste, K. AND Lilleleht, v. 1987. Population ecology of the Common Gull Larus canus in Estonia. Ornis Fennica, 64, 25-26.

RATTISTE, K. AND LiLleleHT, v. 1995. Survival rates of breeding common gulls in Estonia. J. Appl. Stat., 22, 1057-1062.

RISKA, B., PROUT, T. AND TURELL1, M. 1989. Laboratory estimates of heritabilities and genetic correlations in nature. Genetics, 123, 865-871.

SAS INSTITUTE 1NC. 1987. SAS User's Guide: Statistics, Version 5 edn. SAS Institute Inc., Cary, NC.

SCHLUTER, D. AND GUSTAFSSON, L. 1993. Maternal inheritance of condition and clutch size in the collared flycatcher. Evolution, 47, 658-667.

SIMONS, A. M. AND ROFF, D. A. 1994. The effect of environmental variability on the heritabilities of traits of a field cricket. Evolution, 48, 1637-1649.

SMITH, H. G. 1994. Heritability of tarsus length in crossfostered broods of the European starling (Sturnus vulgaris). Heredity, 71, 318-322. 
SMITH, H. G., KÄLlANDER, H. AND NILSSON, J.-Å. 1989. The trade-off between offspring number and quality in the great tit Parus major. J. Anim. Ecol., 58, 383-401.

STEARNS, s. C. 1992. The Evolution of Life Histories. Oxford University Press, Oxford.

TURell, M. 1988. Phenotypic evolution, constant covariances, and the maintenance of additive variance. Evolution, 42, 1342-1347.

VAN NOORDWIJK, A. J., VAN BALEN, J. H. AND SCHARLOO, W. 1980. Heritability of ecologically important traits in the great tit. Ardea, 68, 193-203.

VAN NOORDWIJK, A. J., VAN BALEN, J. H. AND SCHARLOO, W.
1981. Genetic variation in the timing of reproduction in the Great Tit. Oecologia, 49, 158-166.

VAN NOORDWIJK, A. J., VAN BALEN, J. H. AND SCHARLOO, W. 1988. Heritability of body size in a natural population of Great Tit (Parus major) and its relation to age and environmental conditions during growth. Genet. Res., Camb., 51, 149-162.

VIA, s. AND LANDE, R. 1985. Genotype-environment interaction and the evolution of phenotypic plasticity. Evolution, 39, 505-522.

WIGGINS, D. A. 1989. Food availability, growth, and heritability of body size in nestling Tree Swallows (Tachycineta bicolor). Can. J. Zool., 68, 1292-1296. 